\title{
Effect of Oral Administration of Dextran Sulfate on Endogenous Plasma Lipoprotein Lipase and Hepatic Lipase Activities in Healthy Men
}

\author{
Kazumi NinomiYa,* Fumiko SAIto, Hideaki MukaIdA, \\ and Yoshisuke MaruHama \\ First Department of Internal Medicine, Iwate Medical University, \\ Morioka 020, Japan
}

(Received November 2, 1987)

\begin{abstract}
Summary We examined whether or not endogenous plasma lipoprotein lipase (LPL) and hepatic lipase (HL) activities are stimulated by oral administration of dextran sulfate (DS). The diurnal fluctuations of the plasma activities of the lipases were studied together with the diurnal profiles of triglyceride in chylomicrons and in very low density lipoprotein (Chyl-VLDL-TG), and apoproteins (C-II, C-III, and E) in 8 young healthy men during the administration of a test diet and during the administration of the test diet combined with a total daily dosage of $1,800 \mathrm{mg}$ of DS.

Chyl-VLDL-TG decreased before supper and the decrease was more marked in the DS group than in the control group. The diurnal plasma apoproteins C-II, C-III, and E showed a gradual but significant reduction when DS was not given, but the levels did not decrease when DS was administered. In the control group, the LPL activity showed only a minute fluctuation which was characterized by an insignificant increase after each meal. In the DS group, on the other hand, the LPL activity showed a stepwise increase, and the activity before supper $(27.5 \pm 6.6$ $\mathrm{nmol} \mathrm{FFA} / \mathrm{ml} / \mathrm{h}, \mathrm{M} \pm \mathrm{SE})$ was significantly greater $(p<0.05)$ than the activity in the fasting plasma $(8.3 \pm 1.4 \mathrm{nmol} \mathrm{FFA} / \mathrm{ml} / \mathrm{h})$. In contrast, the HL activity did not show any significant fluctuation in either group. Only the HL activity at 12 noon in the DS group $(17.4 \pm 5.5 \mathrm{nmol}$ FFA/ $\mathrm{ml} / \mathrm{h})$ tended to be greater than the activity at $8 \mathrm{a} . \mathrm{m} .(8.8 \pm 1.8 \mathrm{nmol} \mathrm{FFA} /$ $\mathrm{ml} / \mathrm{h})$.
\end{abstract}

Thus, the oral administration of DS was shown to promote the diurnal Chyl-VLDL-TG clearing in healthy men by stimulating the release of LPL into circulation and by maintaining the LPL co-factors such as apoproteins C-II, C-III, and E.

\footnotetext{
*To whom correspondence should be addressed.
} 
Key Words: dextran sulfate, endogenous lipoprotein lipase, endogenous hepatic lipase

It has been demonstrated that the elevation of plasma triglyceride (TG) not only in fasting [1] but also in postprandial state [2] is atherogenic. Clinically, the patients with hypertriglyceridemia have been treated either by diet therapy or by combined diet and drug therapy. Dextran sulfate (DS) is one of the drugs that has been widely used in the treatment of hypertriglyceridemia as well as hypercoagulability. Goto [3] recently demonstrated a long-term benefical effect of DS in the primary prevention of coronary heart disease. The DS Primary Prevention Trial Group also reported the effectiveness of DS on hyperlipidemia and prevention of coronary heart disease [4]. The mechanism of the TG-lowering action of DS has been supposed to be due to the stimulation of the activity and release of lipoprotein lipase (LPL) [5-9]. The intravenous administration of DS liberates the LPL activity into circulation in a manner similar to heparin [8, 10]. However, whether or not the oral administration of DS is also able to release LPL into circulation in man has not yet been determined. If LPL activity increases in plasma by the oral administration of DS after each meal, it probably reduces the postprandial elevation of TG-rich lipoproteins and subsequent atherogenesis.

In this study, we investigated the effect of oral DS administration on diurnal endogenous plasma LPL and hepatic lipase (HL) activities together with lipidapolipoprotein fluctuations in healthy young men fed three controlled meals.

\section{MATERIALS AND METHODS}

Study design. Eight healthy men aged $21.2 \pm 0.4(\mathrm{M} \pm \mathrm{SE})$ years participated in this study. They were not obese, having a body mass index of $21.2 \pm 0.4$, and their body weight had been maintained within $\pm 0.5 \mathrm{~kg}$ during the preceding 2 weeks. Their plasma lipids were normal (total cholesterol, $171 \pm 9 \mathrm{mg} / 100 \mathrm{ml}$; TG, $74 \pm 9 \mathrm{mg} / 100 \mathrm{ml}$; and high density lipoprotein cholesterol, $51 \pm 4 \mathrm{mg} / 100 \mathrm{ml}$ ). They had been on regular Japanese diets of about 2,000 kcal and were not taking any drugs.

The experimental design was explained and informed consent was obtained from each subject. No alcohol was allowed on the day prior to the examination.

After an overnight fast, the first diurnal examination was performed with the test diet alone (control group). The test diet was an ordinary Japanese diet which contained, per day, $285 \mathrm{~g}$ of carbohydrate, $64 \mathrm{~g}$ of protein, and $52 \mathrm{~g}$ of fat (total energy: 1,864 kcal); each meal was given at 8 a.m., 12 noon, and 6 p.m., as shown in Table 1. Blood samples were obtained every $2 \mathrm{~h}$ from 8 a.m. to 8 p.m. in cooled EDTA-tubes and stored at $4^{\circ} \mathrm{C}$. Plasma samples were obtained by refrigerated centrifugation $(3,000 \mathrm{rpm}$ for $20 \mathrm{~min})$ and stored at $-40^{\circ} \mathrm{C}$ until analysis could be performed. 
Table 1. Composition of test diet.

\begin{tabular}{lcccr} 
& Breakfast & Lunch & Supper & Total \\
\hline Carbohydrate (g) & 91 & 103 & 91 & 285 \\
Protein (g) & 19 & 24 & 21 & 64 \\
Fat (g) & 11 & 25 & 16 & 52 \\
Energy (kcal) & 539 & 733 & 592 & 1,864 \\
\hline
\end{tabular}

Carbohydrate was given mainly as rice, and polyunsaturated/saturated ratio of the fat in the test diet was 1.03 .

Seven days later, a similar diurnal examination was carried out again under the same diet, but this time with the administration of a total of $1,800 \mathrm{mg} / \mathrm{day}$ of DS (600 mg, $30 \mathrm{~min}$ after each meal) (DS group). DS (molecular weight of about $7,000)$ known to have a specific stimulating effect on LPL activity was supplied from Kowa Co., Nagoya.

Four of the 8 subjects received the control diet first and the other four subjects received the control diet plus DS first.

Clinical analysis. In this study, chylomicron (Chyl) and very low density lipoprotein (VLDL), were separated as one fraction (density<1.006) from $4 \mathrm{ml}$ of plasma added to $2 \mathrm{ml}$ of $0.10 \mathrm{M} \mathrm{NaCl}$ containing $0.3 \mathrm{~mm}$ EDTA $(d=1.006)$. The ultracentrifugation was performed in a Hitachi 70P-72 ultracentrifuge with a Hitachi RP-65T rotor for $24 \mathrm{~h}$ at $40,000 \mathrm{rpm}$ according to the method of Havel et al. [11].

TG was measured by the method of Ueda [12]. Plasma apolipoproteins C-II, C-III, and E were also measured [13, 14].

Plasma LPL and HL activities were measured by the method of Eckel et al. [15], in which both lipases from plasma were first eluted through a mini-column (Bio-Rad Laboratories, Richmond) packed with heparin-Sepharose CL-6B (Pharmacia, Uppsala). The total TG lipase activity assay was performed using a substrate prepared from lecithin (Pharmacia), $\left[{ }^{14} \mathrm{C}\right]$ triolein (Amersham), non-labeled triolein (Sigma, St. Louis), and serum as an activator. The HL activity assay was performed using the same lecithin-triolein mixture, but in the absence of the serum activator and in the presence of $1.2 \mathrm{M} \mathrm{NaCl}$; these conditions are known to completely inhibit peripheral LPL activity $[15,16]$. The LPL activity was obtained by subtracting the HL activity from the total lipase activity.

Statistical analysis. The differences in the data were evaluated statistically by the paired $t$-test. $p$-Values less than 0.05 were regarded as significant.

\section{RESULTS}

As shown in Table 2, the plasma Chyl-VLDL-TG level increased after lunch and then decreased before supper in both the control and DS groups. Although 
Table 2. Diurnal change in plasma Chyl-VLDL-TG levels $(\mathrm{mg} / 100 \mathrm{ml})$ in control and dextran sulfate-administered group.

\begin{tabular}{llllllll}
\hline & \multicolumn{7}{c}{ Time } \\
\cline { 2 - 8 } & 8 a.m. & 10 a.m. & 12 noon & 2 p.m. & 4 p.m. & 6 p.m. & 8 p.m. \\
\hline Control & $60 \pm 5$ & $53 \pm 4$ & $65 \pm 5$ & $76 \pm 12$ & $74 \pm 16$ & $56 \pm 8$ & $56 \pm 9$ \\
DS & $64 \pm 8$ & $60 \pm 8$ & $61 \pm 13$ & $72 \pm 11$ & $54 \pm 6$ & $50 \pm 5$ & $59 \pm 13$ \\
\hline
\end{tabular}

Figures are means \pm SE. Chyl-VLDL-TG, Triglyceride in chylomicrons and very low density lipoprotein; DS, dextran sulfate.

Table 3. Diurnal change in plasma apoprotein C-II, C-III, and $\mathrm{E}$ levels $(\mathrm{mg} / 100 \mathrm{ml})$ in control and dextran sulfate-administered group.

\begin{tabular}{lccccccc}
\hline \multicolumn{7}{c}{ Time } \\
\cline { 2 - 7 } & 8 a.m. & 10 a.m. & 12 noon & 2 p.m. & 4 p.m. & 6 p.m. & 8 p.m. \\
\hline C-II & & & & & & & \\
Control & $3.8 \pm 0.4$ & $3.5 \pm 0.4$ & $3.7 \pm 0.4$ & $3.3 \pm 0.4$ & $3.2 \pm 0.3^{*}$ & $3.1 \pm 0.2^{*}$ & $3.2 \pm 0.4$ \\
DS & $3.1 \pm 0.3$ & $2.9 \pm 0.3$ & $3.1 \pm 0.3$ & $3.3 \pm 0.4$ & $3.0 \pm 0.2$ & $3.1 \pm 0.3$ & $3.0 \pm 0.3$ \\
C-III & & & & & & & \\
Control & $9.3 \pm 1.0$ & $8.3 \pm 1.0$ & $8.3 \pm 1.1^{*}$ & $7.7 \pm 0.6^{*}$ & $7.8 \pm 0.6$ & $6.9 \pm 0.6^{*}$ & $7.4 \pm 0.8^{*}$ \\
DS & $8.1 \pm 0.9$ & $7.5 \pm 1.0$ & $7.4 \pm 1.0$ & $7.6 \pm 0.6$ & $6.9 \pm 0.8$ & $7.0 \pm 0.7$ & $7.1 \pm 0.7$ \\
E & & & & & & & \\
Control & $4.0 \pm 0.5$ & $3.4 \pm 0.5^{*}$ & $3.5 \pm 0.4$ & $3.5 \pm 0.5$ & $3.4 \pm 0.4$ & $3.0 \pm 0.4 *$ & $2.5 \pm 0.3^{*}$ \\
DS & $3.5 \pm 0.3$ & $3.3 \pm 0.4$ & $3.4 \pm 0.5$ & $3.3 \pm 0.4$ & $3.2 \pm 0.4$ & $3.2 \pm 0.4$ & $3.1 \pm 0.5$ \\
\hline
\end{tabular}

Figures are means \pm SE. ${ }^{*} p<0.05$ for difference from fasting $(8$ a.m.) value. DS, Dextran sulfate.

the changes were not significant, the decrease was more marked in the DS group than in the control.

The diurnal changes in apoprotein C-II, C-III, and E levels are shown in Table 3. In the control group, apoprotein C-II decreased significantly from the starting value of $3.8 \mathrm{mg} / 100 \mathrm{ml}$ to $3.2 \mathrm{mg} / 100 \mathrm{ml}$ at 4 p.m. $(p<0.05)$ and to 3.1 $\mathrm{mg} / 100 \mathrm{ml}$ at 6 p.m. $(p<0.05)$. Apoprotein C-III also decreased significantly from $9.3 \mathrm{mg} / 100 \mathrm{ml}$ at 8 a.m. to $8.3 \mathrm{mg} / 100 \mathrm{ml}$ at 12 noon $(p<0.05), 7.7 \mathrm{mg} / 100 \mathrm{ml}$ at 2 p.m. $(p<0.05), 6.9 \mathrm{mg} / 100 \mathrm{ml}$ at 6 p.m. $(p<0.05)$, and to $7.4 \mathrm{mg} / 100 \mathrm{ml}$ at 8 p.m. $(p<0.05)$. Similarly, apoprotein E decreased from $4.0 \mathrm{mg} / 100 \mathrm{ml}$ at 8 a.m. to $3.4 \mathrm{mg} / 100 \mathrm{ml}$ at $10 \mathrm{a} . \mathrm{m} .(p<0.05)$ and to $3.0 \mathrm{mg} / 100 \mathrm{ml}$ at 6 p.m. $(p<0.05)$. In the DS group, however, the apoproteins C-II, C-III, and E remained stable; and, if present, there was only a negligible decrease in these apoproteins.

As shown in Table 4, LPL activity in the control group showed only an insignificant diurnal fluctuation which was characterized by an increase after each 
Table 4. Diurnal change in endogenous plasma lipoprotein lipase activity and hepatic lipase activity in control group and dextran sulfate group.

\begin{tabular}{lrrrrrrr}
\hline & \multicolumn{7}{c}{ Time } \\
\cline { 2 - 7 } & 8 a.m. & 10 a.m. & 12 noon & 2 p.m. & 4 p.m. & 6 p.m. & 8 p.m. \\
\hline LPL (nmol FFA/ml/h) & & & & & & \\
Control & $7.9 \pm 1.7$ & $13.5 \pm 2.9$ & $9.8 \pm 2.4$ & $17.7 \pm 8.6$ & $10.6 \pm 1.7$ & $13.5 \pm 5.1$ & $22.2 \pm 13.2$ \\
DS & $8.3 \pm 1.4$ & $10.2 \pm 2.1$ & $12.4 \pm 1.5$ & $23.2 \pm 8.0$ & $14.8 \pm 3.2$ & $27.5 \pm 6.6 *$ & $38.2 \pm 13.5$ \\
HL (nmol FFA/ml/h) & & & & & & \\
Control & $8.0 \pm 1.2$ & $5.6 \pm 1.1$ & $9.3 \pm 2.1$ & $9.2 \pm 2.5$ & $7.6 \pm 2.1$ & $7.0 \pm 2.0$ & $5.3 \pm 1.1$ \\
DS & $8.8 \pm 1.8$ & $6.1 \pm 1.3$ & $17.4 \pm 5.5$ & $8.3 \pm 1.8$ & $9.5 \pm 2.8$ & $10.0 \pm 2.2$ & $9.0 \pm 1.6$ \\
\hline
\end{tabular}

Figures are mean \pm SE. ${ }^{*} p<0.05$ for difference from fasting ( 8 a.m.) value. LPL, Lipoprotein lipase; HL, hepatic lipase; DS, dextran sulfate.

meal. On the other hand, the administration of DS induced an increase in LPL activity gradually; the value at $6 \mathrm{p} . \mathrm{m} .(27.5 \pm 6.6 \mathrm{nmol} \mathrm{FFA} / \mathrm{ml} / \mathrm{h})$ was statistically significant $(p<0.05)$ when compared with the value at 8 a.m. $(8.3 \pm 1.4 \mathrm{nmol}$ FFA/ $\mathrm{ml} / \mathrm{h}$ ). HL activity did not show any significant fluctuation from morning until evening in both the control group and the DS group except for a slight increase with considerable variation at the noon period.

\section{DISCUSSION}

The TG-lowering effect of DS in man has been widely recognized [17-20]. Very recently, Goto [3] and the DS Primary Prevention Trial Group [4] summarized the results of long-term oral administration of DS for the primary prevention of atherosclerotic diseases showing a significant reduction in the occurrence of the diseases in the DS-treated group, and their results seem to suggest the possible amelioration of postprandial hypertriglyceridemia under the DS treatment. This might have a clinical implication since the increase in postprandial TG-rich lipoproteins is suggested to promote lipid deposition in the arterial wall [2].

The DS action upon LPL activation and release has been shown to resemble the well-known heparin action [8, 10,21]. Thus, intravenous DS administration can decrease VLDL-TG significantly [17, 22]. Furthermore, Nakamura and Hara [19] revealed the effectiveness of oral DS administration in the single dosage of $3.6 \mathrm{~g}$ in the reduction of VLDL-TG, whereas they found only a small reduction in the VLDL-TG after the oral administration of $1.8 \mathrm{~g}$ DS. In the present study, we administered $1.8 \mathrm{~g}$ of DS per day to normolipidemic healthy men and also found from diurnal observation a definite but insignificant decrease in Chyl-VLDL$\mathrm{TG}$ in the period before supper.

It has been demonstrated that almost all apoproteins $\mathrm{C}$ and $\mathrm{E}$ in VLDL are removed and become components of HDL when VLDL is hydrolyzed after heparin 
injection [23-25]. Takeuchi et al. [22, 26] showed that there was a significant decrease in VLDL and a comparable increase in HDL accompanied by an apparent exchange of apoproteins C-II, C-III, and E between VLDL and HDL after the intravenous administration of $300 \mathrm{mg}$ of DS. These authors, however, found no significant change in plasma total levels of apoproteins C-II, C-III, and E [22, 26]. In our study, apoprotein C-II, C-III, and E levels did not change during the day in the DS group, while these apoproteins showed significantly decreased diurnal levels in the control group, in which DS was not given. Therefore, DS may enhance the new supply of these exchangeable apoproteins, the known co-factors for LPL action.

Enhancement of LPL activity by DS has been demonstrated by an in vitro study [27] and also by an in vivo study of rats and dogs [8]. In an investigation on humans, DS given intravenously accelerated the activity not only of LPL but also of HL [10]. Murase noted a marked increase in free fatty acids and a minute increment of circulating LPL activity after the oral administration of $3.0 \mathrm{~g}$ of DS [28], however, he did not carry out statistical analysis of the LPL increment. In the present study we found a variable increase in the activity of LPL but not in the activity of HL during the oral administration of DS in the total dosage of $1.8 \mathrm{~g}$ between $8 \mathrm{a} . \mathrm{m}$. and $8 \mathrm{p} . \mathrm{m}$. Statistically, the increase in LPL activity during the DS study was significant before supper. Interestingly, a definite decrease was also noted in the Chyl-VLDL-TG level in this pre-supper period, suggesting that the DS stimulated Chyl-VLDL-TG hydrolysis.

In conclusion, our study indicates that the oral administration of DS enhances the diurnal LPL activity in circulating plasma of healthy men associated with the maintenance of the otherwise decreasing LPL.

\section{REFERENCES}

1. Carlson, L.A., and Bottiger, L.E. (1972): Ischemic heart disease in relation to fasting values of plasma triglycerides and cholesterol: Stockholm prospective study. Lancet, 1, 865-868.

2. Zilversmit, D.B. (1979): Atherogenesis: A postprandial phenomenon. Circulation, 60, 473485.

3. Goto, Y. (1986): Cholesterol level of Japanese in past twenty years and primary prevention study by dextran sulfate, in Atherosclerosis VII (International Congress Series 696), ed. by Fidge, N.H. and Nestel, P.J., EXCERPTA MEDICA, Amsterdam, pp. 9-14.

4. MDS Primary Prevention Trial Group (1987): Effect of dextran sulfate (MDS) on prevention of ischemic heart disease in double blind primary prevention trial. I. Clin. Biochem. Nutr., 2, 55-70.

5. Cohen, H., and Tudhope, G.R. (1956): Dextran sulfate: Use as an anticoagulant, and action in lowering serum cholesterol. Brit. Med. J., 2, 1023-1027.

6. Shigeta, Y., Nakamura, K., Hoshi, M., Kim, M., and Abe, H. (1967): Effect of dextran sulfate on plasma lipoprotein lipase activity in obese subjects and diabetic patients. Diabetes, 16, 238-241.

7. Matsuoka, N., Shirai, K., Saito, Y., and Kumagai, A. (1982): Effect of dextran sulfate on the interaction between very low density lipoprotein and lipoprotein lipase. Biochim. Biophys. Acta, 712, 221-224. 
8. Tani, H., Ishihama, Y., Nakajima, K., Kimata, H., and Tukamoto, M. (1979): On the absorption of dextran sulfate, in Dextran Sulfate no Rinsho (MDS Conference), ed. by Tanaka, K. and Matsuoka, S., Ijishuppansha, Tokyo, pp. 3-7.

9. Iverius, P.H., Lindahl, U., Egelrud, T., and Olivecrona, T. (1972): Effect of heparin on lipoprotein lipase from bovine milk. J. Biol. Chem., 247, 6610-6616.

10. Murase, T., Tanaka, K., Itakura, H., Akanuma, Y., and Kosaka, K. (1979): On the hypolipidemic action of dextran sulfate-effect of the iv administration of plasma triglycerides and two triglyceride lipases. Jpn. J. Clin. Exp. Med., 12, 779-781.

11. Havel, R.J., Eder, H.A., and Bragdon, J.H. (1955): The distribution and chemical composition of ultracentrifugally separated lipoproteins in human serum. J. Clin. Invest., 34, 13451353.

12. Ueda, K. (1980): Neutral fat. Methods of enzymatic determination. Med. Technol., 8, 10141019.

13. Apolipoprotein Research Group (1986): Determination by the SRID method of normal values of serum apolipoproteins (A-I, A-II, B, C-II, C-III, and E) in normolipidemic healthy Japanese subjects. J. Clin. Biochem. Nutr., 1, 73-88.

14. Itakura, K., Matsudate, T., Sakurai, T., Hashimoto, S., Ito, K., Hirata, M., and Nakamura, K. (1986): Single radial immunodiffusion of serum apolipoproteins C-II, C-III and Epretreatment of samples with surfactant. Clin. Chim. Acta, 161, 275-282.

15. Eckel, R.H., Steiner, L., Kern, P.A., and Paterniti, J.R., Jr. (1982): Plasma lipolytic activity in humans: Evidence of hormonal regulation. Circulation, 66, II, 282 (abstract).

16. Berr, F., Eckel, R., and Kern, F., Jr. (1985): Plasma decay of chylomicron remnants is not affected by heparin stimulated plasma lipolytic activity in normal fasting man. J. Lipid Res., 26, 852-859.

17. MDS Primary Prevention Trial Group (1985): Effect of dextran sulfate on prevention of ischemic heart disease by double blind primary prevention trial. J. Jpn. Atheroscler. Soc., 13, 507-514.

18. Yamada, K., Kuzuya, H., and Noda, M. (1961): Studies on some actions of sulfated polysaccharides on atherosclerosis. I. Toxicity, lipolytic action and anticoagulant activity. Jpn. Cir. J., 25, 497-502.

19. Nakamura, H., and Hara, T. (1978): Metabolic alteration of plasma lipoproteins-changes of lipoprotein compositions by dextran sulfate. J. Jpn. Geriatr., 15, 362-367.

20. Namba, T. (1981): Effect of MDS Kowa on hypo-HDL cholesterolemia. Progr. Med., 1, 95-103.

21. Hara, T., Nakaya, N., and Goto, Y. (1979): Effect of dextran sulfate on the lipoprotein composition, in Dextran Sulfate no Rinsho (MDS Conference), ed. by Tanaka, K. and Matsuoka, S., Ijishuppansha, Tokyo, pp. 21-26.

22. Takeuchi, N., Murase, M., Nishiyama, T., Ochi, M., and Tokunaga, K. (1985): Effects of dextran sulfate on serum lipoproteins. Jpn. J. Clin. Chem., 14, 102-111.

23. Glangeaud, M.C., Eisenberg, S., and Olivecrona, T. (1977): Very low density lipoprotein. Dissociation of apolipoprotein $\mathrm{C}$ during lipoprotein lipase induced lipolysis. Biochim. Biophys. Acta, 486, 23-35.

24. Tam, S.P., Dory, L., and Rubinstein, D. (1981): Fate of apolipoprotein C-II, C-III and E during lipolysis of human very low density lipoproteins. J. Lipid Res., 22, 641-651.

25. Blum, C.B. (1982): Dynamics of apolipoprotein E metabolism in humans. J. Lipid Res., 23, 1308-1316.

26. Takeuchi, N., Murase, M., Tokunaga, K., Ochi, M., Go, S., Akutsu, H., and Mizuno, Y. (1986): Effect of dextran sulfate on the distributions of serum apolipoproteins in normoand hyperlipidemic subjects. J. Jpn. Atheroscler. Soc., 14, 415-419.

Vol. 5, No. 1, 1988 
27. Matsuoka, N., Saito, Y., and Yoshida, S. (1986): Effects of dextran sulfate on stabilization of milk lipoprotein lipase and VLDL triglyceride hydrolysis in vitro. Tohoku J. Exp. Med., 149, 61-66.

28. Murase, T. (1979): Hypolipidemic effect of dextran sulfate, in Dextran Sulfate no Rinsho (MDS Conference), ed. by Tanaka, K. and Matsuoka, S., Ijishuppansha, Tokyo, pp. 27-29. 